\title{
Preparation and in vitro characterization of AL-Beads containing carbamazepine and/or levetiracetam
}

\author{
Afife Büşra UĞUR ${ }^{1}$ (D) , Büşra KANDİLLİ ${ }^{1}$ (D) , Meltem ÇETİN 1 * (D) , Fatma DEMİRKAYA MİLOĞLU 2 (D) \\ 1 Atatürk University, Faculty of Pharmacy, Department of Pharmaceutical Technology, Erzurum, Turkey. \\ 2 Atatürk University, Faculty of Pharmacy, Department of Analytical Chemistry, Erzurum, Turkey. \\ * Corresponding Author. E-mail: melcetin@hotmail.com (M.Ç.); Tel. +90 4422315236
}

Received: 26 September 2018 / Revised: 19 November 2018 / Accepted: 22 November 2018

\begin{abstract}
The purpose of the present study was to prepare only levetiracetam (LEV) or carbamazepine (CBZ) or their combination (LEV+CBZ)-loaded alginate (AL) beads for oral administration to treat epilepsy and to evaluate their in vitro characteristics. AL beads were prepared using ionotropic gelation method and lyophilized. The bead formulations were evaluated for particles size, surface morphology, encapsulation efficiency and in vitro drug release in $\mathrm{PB}$ pH 6.8 and $\mathrm{HCl}$ pH 1.2 release mediums. FT-IR was also used to characterize the beads. The mean particle sizes of wet and lyophilized AL beads were in range of $1.609 \pm 0.073-1.779 \pm 0.078 \mathrm{~mm}$ and $1.075 \pm 0.182-1.275 \pm 0.138 \mathrm{~mm}$, respectively. The encapsulation efficiency (EE\%) values of bead formulations were in the range of 18.74-24.65\% for LEV and $90.36-94.03 \%$ for CBZ. The $\mathrm{pH}$ of the medium affects the swelling behaviours of AL beads and the degree of swelling of $\mathrm{AL}$ beads increased with increase of $\mathrm{pH}$ of release medium, due to exchange of the $\mathrm{Ca}^{2+}$ ion with $\mathrm{Na}^{+}$. Besides, the $\mathrm{pH}$ of the release medium and the high water solubility of LEV affected the drug release rate from beads. AL beads might be useful to use for oral administration of LEV and CBZ to obtain additive/synergistic effect in a combined treatment of epilepsy.
\end{abstract}

KEYWORDS: Alginate beads; carbamazepine; epilepsy; in vitro characteristics; levetiracetam.

\section{INTRODUCTION}

Epilepsy is one of the most common and most disabling neurological disorder and affects all age groups. It is characterized by an enduring predisposition to generate epileptic seizures, which is is a transient behavioural change that might be objective signs or subjective symptoms. Patients with uncontrolled seizures have significant morbidity and mortality risks and also experience face social stigma and discrimination [1, 2].

Antiepileptic drugs (AEDs) are used to decrease the frequency and/or severity of seizures in people with epilepsy. Despite the availability of many AEDs (CBZ, phenobarbital, phenytoin, lamotrigine, LEV, lacosamide, retigabine, perampanel etc.) in the market for completely controlling the seizures a significant proportion of patients by monotherapy. However, there is still approximately $30 \%$ of patients refractory to the available drug treatment. In the drug treatment for epilepsy, the goal is minimizing adverse drug effects while maximizing seizure control, thus improving the quality of life of patient. For the patients with drug-resistant epilepsy, two or more AEDs (polytherapy) are necessary to control their seizures. In polytherapy, the combination of antiepileptic drugs with diverse molecular mechanisms of action seem to be more favorable to protect efficaciously and satisfactorily the patients against seizures than monotherapy [3,4] Florek-Luszczki reported that the combinations of LEV with CBZ, topiramate, phenytoin and vigabatrin, were supra-additive in terms of seizure suppression, thus, the synergistic interactions between LEV and the other antiepileptic drugs in combinations might be useful in clinical practice [3].

LEV is an AED used in the treatment of partial seizures, and tonic-clonic seizures and myoclonic seizures. FDA approved the use of the oral formulation (tablet), parenteral (iv infusion) formulations and 3Dprinted orodispersible tablets (ODT) as adjunctive therapy for treatment of myoclonic seizure, focal seizures and primary generalized seizures in 1999, 2006 and 2015, respectively [5, 6]. LEV, which is chemically unrelated to other AEDs, has distinct mechanism of action, fewer drug interactions and favorable safety profile [5]. The mechanisms of LEV for its antiepileptic effects are not clearly defined. The most relevant mechanism of LEV action is thought to be through binding of LEV to synaptic vesicle protein 2A (SV2A), which mediates

How to cite this article: Uğur $A B$, Kandilli $B$, Çetin $M$, Demirkaya Miloğlu F. Preparation and in vitro characterization of AL-beads containing carbamazepine and/or levetiracetam. J Res Pharm. 2019; 23(4): 642-651. 
calcium-dependent vesicular neurotransmitter release, and the binding decreases the rate of vesicle release. LEV has very high (96\%) bioavailability. It is not extensively metabolized (about $66 \%$ of LEV is excreted unchanged by kidneys) and Cytochrome P450 system does not affect the metabolism of LEV. Its plasma halflife is approximately 6 to 8 hours in adults. There are conventional tablet, tablet for suspension, tablet-extended release, ODT, oral solution and IV-infusion formulations of LEV in the market [7]. Adverse effects observed with use of LEV are somnolence, headache, aggression, fatigue, confusion, increased diastolic blood pressure, vomiting, anorexia, nausea, rhinitis leukopenia, etc. [5].

CBZ is used for the treatment of epilepsy (partial seizures with complex symptomatology, generalized tonic seizures and mixed seizure patterns), trigeminal neuralgia, and psychiatric disorders $[8,9]$.

The metabolism of CBZ is reported to be less susceptible to inhibition by other but some drugs inhibit the metabolism of CBZ by the cytochrome P450 isoenzyme CYP3A4, thus, the plasma concentration of CBZ and associated toxicity increase. CBZ has a variable bioavailability of 85 to $100 \%$. It is extensively metabolised in the liver, in particular by the cytochrome P450 isoenzymes CYP3A4 and CYP2C8. The mean plasma halflife of CBZ on repeated dosage is approximately 12 to 24 hours in adults [10].

$\mathrm{CBZ}$ is available as suspensions, solutions, conventional tablets, chewable tablets, extended-release capsule and extended-release tablets [7, 9]. The most common side effects of CBZ include ataxia, nausea, drowsiness, dizziness and vomiting [9].

Sodium $\mathrm{AL}$, which is extracted from brown algae, is a polysaccharide and soluble in water forming viscous solution. AL consists of $\alpha$-L-guluronic acid $(\mathrm{G})$ and 1,4-linked $\beta$-D-mannuronic $(\mathrm{M})$ residues arranged randomly along the chains. It undergoes ionic gelatin in the presence of divalent cations such as $\mathrm{CaCl}_{2}$ in an aqueous medium. AL beads prepared using $\mathrm{CaCl}_{2}$ have been widely used for drug delivery applications, because, AL alginates is a natural, biocompatible, polyanionic, non-toxic copolymer $[11,12,13]$.

In the light of this information, the purpose of the present study was to prepare and in vitro characterize only LEV or CBZ or their combination (LEV+CBZ)-loaded AL beads for treatment of epilepsy to increase the effectiveness of the active substances and reduce their side effects.

\section{RESULTS AND DISCUSSION}

AL is a hydrophilic polymer and has mucoadhesive properties due to its anionic charge. It is widely used in the design of drug delivery systems. The guluronic acid in AL has high affinity for divalent cations especially $\mathrm{Ca}^{+2}$. The interaction of guluronic acid with $\mathrm{Ca}^{+2}$ causes the formation of 3-D hydrogel matrices [14, 15].

In this study, AL beads were prepared successfully by ionotropic gelation method using $\mathrm{CaCl}_{2}$ as crosslinking agent and in vitro characterized.

\subsection{The particle size and surface morphology of beads}

The particle sizes of wet and dry beads were determined using Vernier calipers and given in Table 1.

Table 1. The particles sizes of AL beads $(X \pm S D ; n=150)$.

\begin{tabular}{lcc}
\hline Formulation & $\begin{array}{c}\text { Particles size of } \\
\text { wet beads } \\
(\mathbf{m m})\end{array}$ & $\begin{array}{c}\text { Particles size of } \\
\text { lyophilized beads } \\
(\mathbf{m m})\end{array}$ \\
\hline B & $1.609 \pm 0.073$ & $1.075 \pm 0.182$ \\
LEV+CBZ & $1.744 \pm 0.082$ & $1.275 \pm 0.138$ \\
LEV 30 & $1.705 \pm 0.078$ & $1.095 \pm 0.118$ \\
LEV 150 & $1.715 \pm 0.077$ & $1.133 \pm 0.086$ \\
CBZ 120 & $1.735 \pm 0.111$ & $1.242 \pm 0.106$ \\
CBZ 150 & $1.779 \pm 0.078$ & $1.261 \pm 0.109$ \\
\hline
\end{tabular}

$\mathrm{X}$ : mean; SD: standard deviation

When the particle sizes of the wet beads were evaluated, it was found that the particle sizes of the beads with the presence of the drug/drugs were significantly increased ( $p<0.05$, compared to the particle size of wet blank beads). Besides, the particles sizes of LEV 30 and LEV 150 formulations were compared, it was observed that there was no significant change in particle size of beads by increasing the amount of LEV in the formulation $(p>0.05)$. However, there was a statistically significant increase $(p<0.05)$ in particle size of CBZ 150 formulation with increasing CBZ content in the formulation compared to the particle size of the CBZ 120 
formulation. When the particles sizes of both LEV 30 and LEV+CBZ formulations, which are prepared using LEV in the same amount, were evaluated, CBZ presence increased the particle size of LEV+CBZ beads $(p<0.05)$. Conversely, there was no a significant change in the particle sizes of the CBZ 120 and LEV+CBZ formulations containing CBZ in the same amount $(\mathrm{p}>0.05)$. LEV presence did not have a significant effect on the size of LEV+CBZ beads.

Furthermore, there was a significant decrease in the particle sizes of all the beads due to shrinkage after lyophilization ( $p<0.05$ compared to the particle size of wet bead formulations).

The obtained digital photographs of the wet and lyophilized AL beads were shown in Figure 1. The SEM images of lyophilized AL beads containing drug/drugs showed that the beads were shrunken after lyophilization (Figure 2). Zohar-Perez et al. [16] reported that after freeze-drying, the differences in the volume, roundness and surface morphology of AL beads occurred. The changes are partially as a result of bead shrinkage.

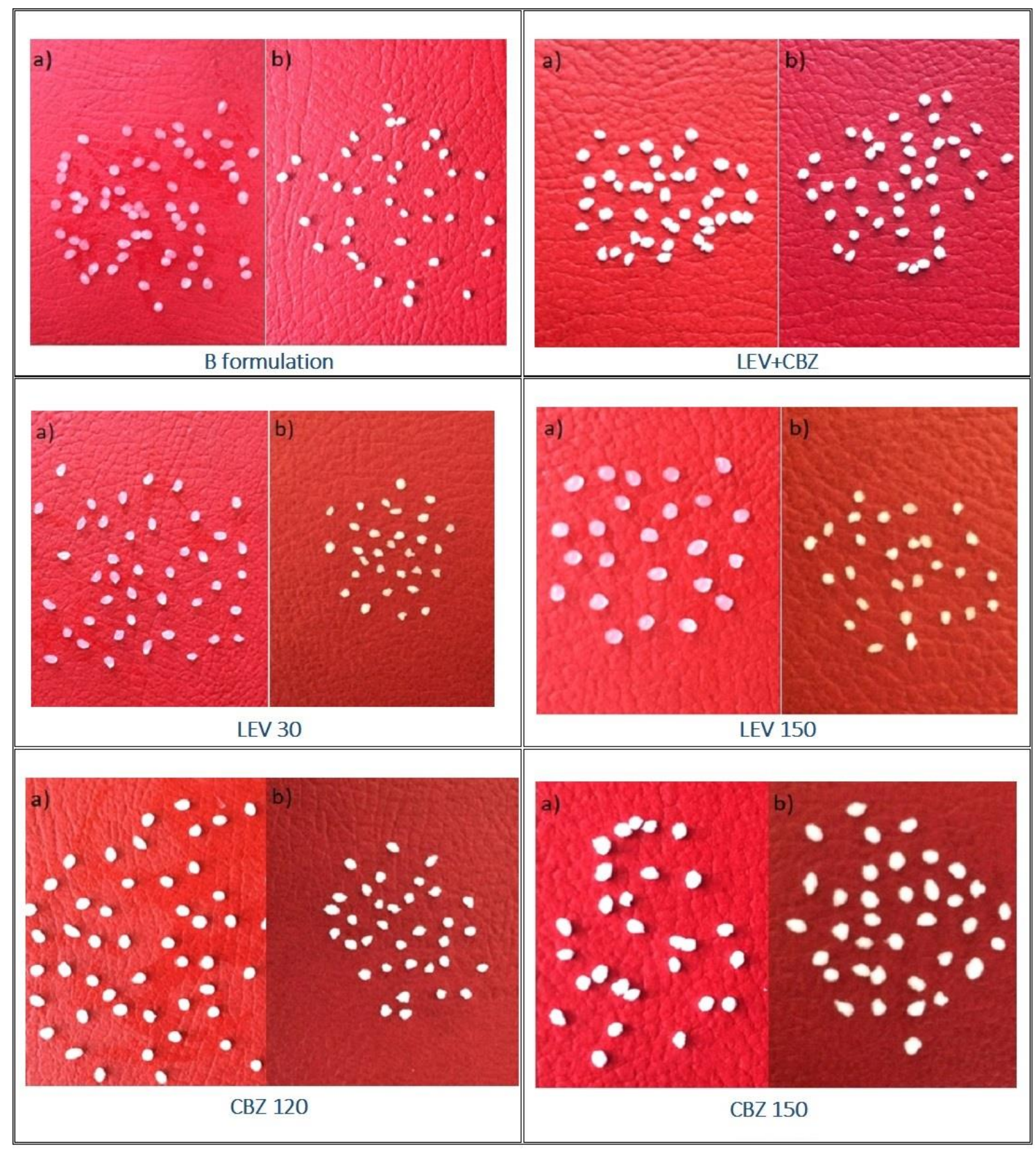

Figure 1. The digital photographs of bead formulations; a) the wet beads b) lyophilized beads. 


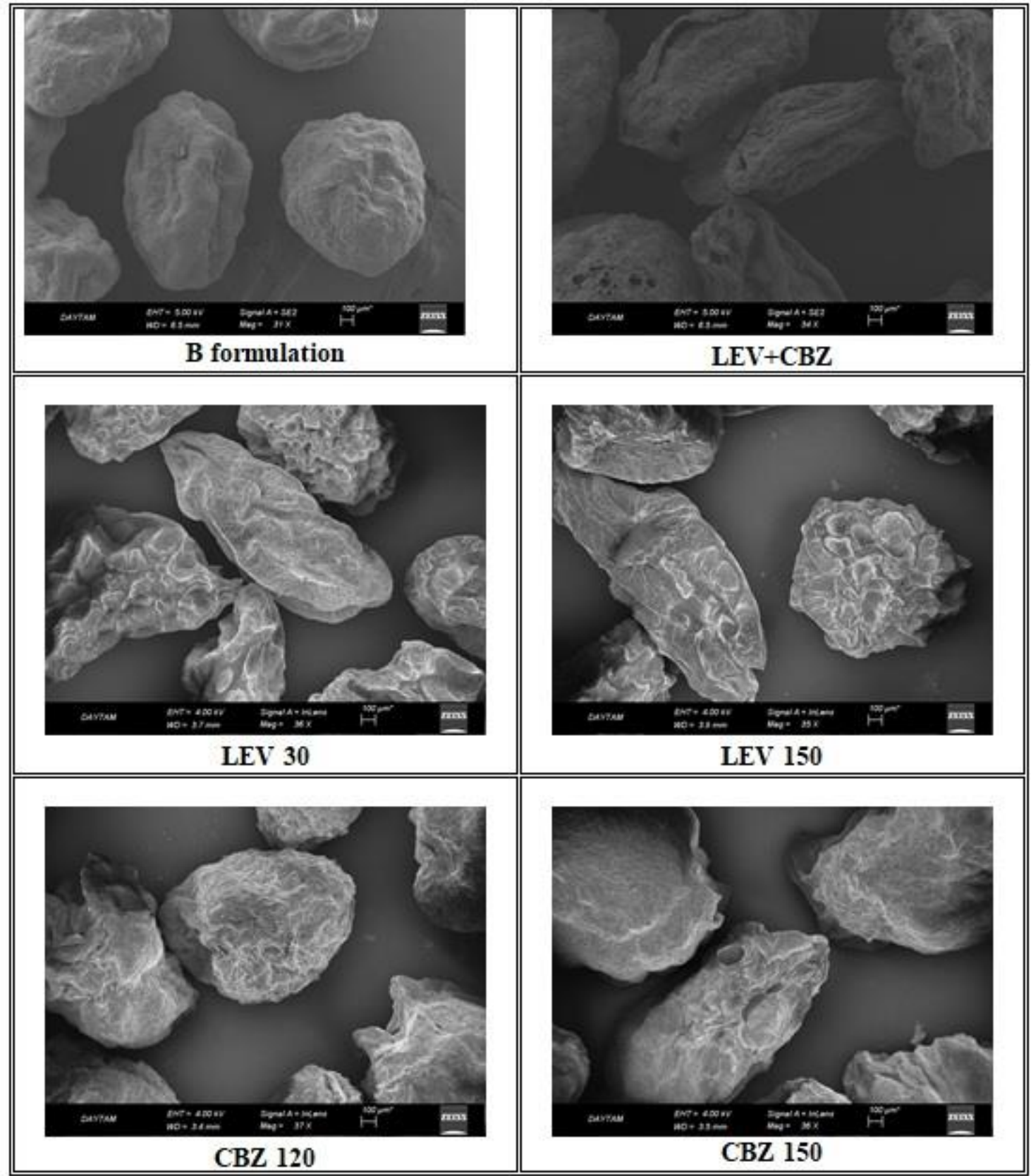

Figure 2. The SEM images of lyophilized bead formulations.

\subsection{FT-IR analysis}

FT-IR spectra were examined to assess whether there is any interaction between the active substances and the bead formulation ingredients (Figure 3). The FT-IR spectrum of the blank bead formulation was quite similar to the FT-IR spectra of all the bead formulations containing the active substances and no different any peak was observed. This indicates that there was no interaction between the active substances and the other formulation components. Najafi-Soulari et al. [17] prepared alginate beads containing extract and evaluated the FT-IR spectra to determine if there was no interaction between the extract and the other formulation components. There was no any a different peak in the spectra of the blank bead formulation and formulation containing the extract and therefore, it was concluded that there was no interaction between the functional groups of alginate and the components of the extract. 




Figure 3. FT-IR spectra of LEV, CBZ and all bead formulations.

\subsection{The drug content of beads}

The EE and drug loading capacity (DL) for the each formulation were calculated and the results were shown in Table 2. There was no a significant difference between the EE\% values of LEV 30 and LEV+CBZ formulations $(p>0.05)$ and also the EE\% values of CBZ 120 and LEV+CBZ formulations ( $p>0.05)$. For LEV+CBZ formulation, the addition of LEV or CBZ to the formulation did not affect the EE\% of the other drug. Several critical factors (the solubility of drug, the concentrations of polymer and cross-linking agent and hardening time etc.) influence the drug loading in beads. While the drug entrapment in the beads increases with increasing the concentrations of polymer and cross-linking agent to a certain value, it decreases with an increase in the hardening time due to longer exposures which results in the release of drug from the matrix into outer aqueous phase [18]. In our study, the obtained low EE\% values for LEV might be due to its high solubility in water and result in drug leakage to the aqueous medium.

The EE\% of CBZ with low water solubility for CBZ 120 and CBZ 150 formulations was found to be 90.36-94.03\%. High EE\% is achieved for water-insoluble drugs [19].

In this study, the difference between the EE\% of LEV 30 and LEV 150 formulations was statistically significant $(\mathrm{p}<0.05)$. A significant reduction in EE\% was observed with increasing LEV amount. Patel et al. [20] evaluated the effect of the concentration of the active substance used during the beads preparation on the EE\%. They used metronidazole, which is an active substance with a high water solubility, as a model drug and obtained a lower EE at a high active substance concentration.

Table 2. The EE \% and DL\% values of bead formulations $(n=9)$

\begin{tabular}{ccc}
\hline Formulation & $\begin{array}{c}\text { EE } \\
(\mathbf{X} \pm \text { SD; } \%)\end{array}$ & $\begin{array}{c}\text { DL } \\
(\mathbf{X} \pm \text { SD; } \%)\end{array}$ \\
\hline LEV+CBZ & $24.65 \pm 1.69(\mathrm{LEV})$ & $0.38 \pm 0.02(\mathrm{LEV})$ \\
LEV 30 & $93.45 \pm 3.76(\mathrm{CBZ})$ & $5.83 \pm 0.39(\mathrm{CBZ})$ \\
LEV 150 & $23.66 \pm 0.41$ & $0.48 \pm 0.01$ \\
CBZ 120 & $18.74 \pm 1.01$ & $1.91 \pm 0.11$ \\
CBZ 150 & $90.36 \pm 4.90$ & $7.27 \pm 0.39$ \\
\hline
\end{tabular}

\footnotetext{
$\mathrm{X}$ : mean; SD: standard deviation
} 


\subsection{Swelling properties of AL-beads}

Swelling behaviors of bead formulations were investigated in $\mathrm{HCl} \mathrm{pH} 1.2$ and also $\mathrm{PB}$ pH 6.8 and were shown in Figure 4 and 5. When compared the swelling \%values in $\mathrm{PB}$ pH 6.8 and $\mathrm{HCl}$ pH 1.2 mediums, much more swelling of the beads at PB pH 6.8 was observed $(\mathrm{p}<0.05)$. Similar results were reported by previous studies $[12,21,22]$.

\section{pH 6.8}

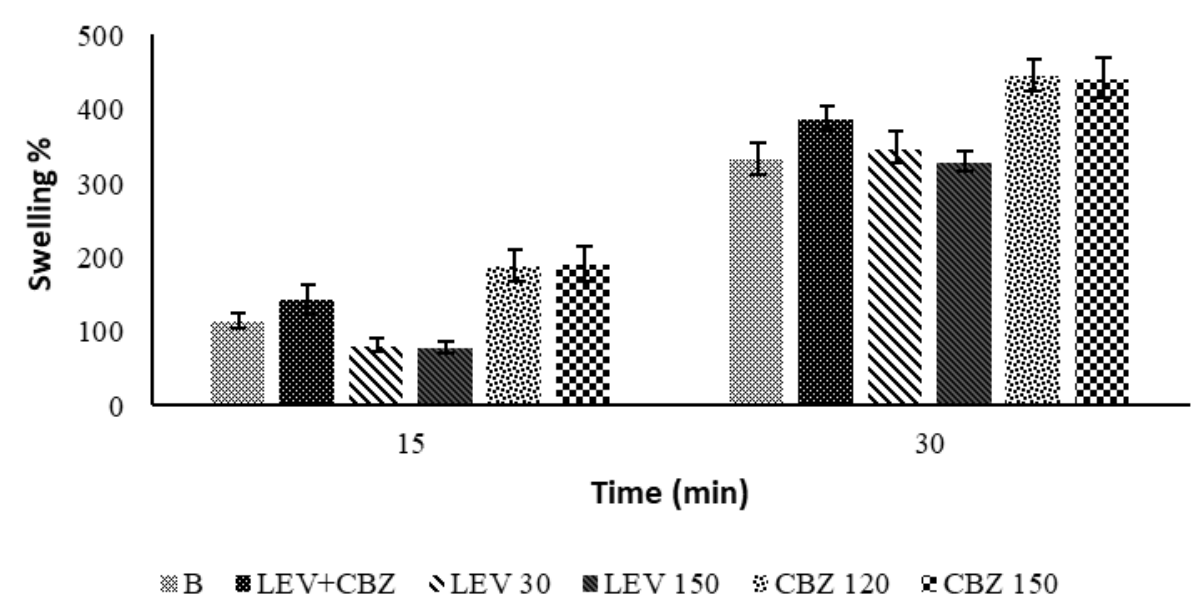

Figure 4. Swelling\% values of bead formulations in $\mathrm{PB}$ pH $6.8(\mathrm{n}=6 ; \mathrm{X} \pm \mathrm{SD})$.

$$
\mathrm{pH} 1.2
$$

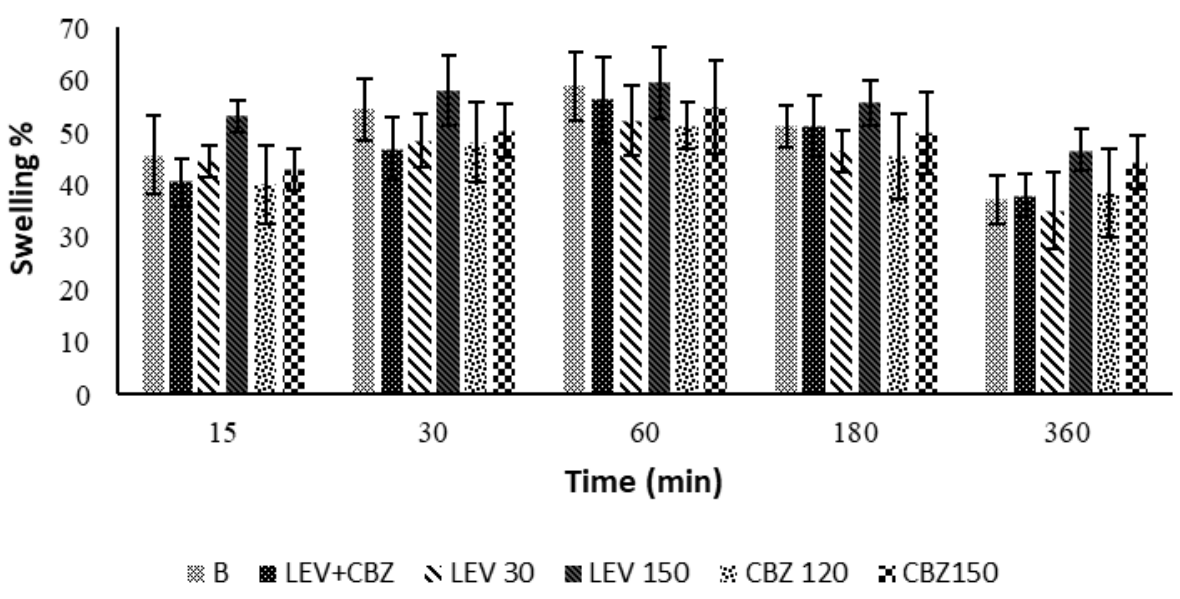

Figure 5. Swelling\% values of bead formulations in $\mathrm{HCl} \mathrm{pH} 1.2(\mathrm{n}=6 ; \mathrm{X} \pm \mathrm{SD})$.

The $\mathrm{pH}$ of the medium affects the swelling behaviours of AL beads. In an acidic $\mathrm{pH}$ below the $\mathrm{pKa}$ of alginate (3.2 and 4), the formation of $\mathrm{COOH}$ groups results in the reduction in the electrostatic repulsion and the formation of intermolecular hydrogen bond, in this way, the restriction of the relaxation of polymer chains and the formation of more compact network was observed. At higher $\mathrm{pH}$, the $\mathrm{COO}$ - groups due to the exchange of the $\mathrm{Ca}^{+2}$ ion of crosslinking agent with monovalent ions $\left(\mathrm{Na}^{+1} \mathrm{or} \mathrm{K}^{+1}\right)$ in medium are formed. As a result, the electrostatic repulsion among $\mathrm{COO}^{-}$groups increases and higher swelling\% values for beads due to the expansion of matrix structure was obtained [23, 24].

\subsection{In vitro release studies}

At PB pH 6.8 release medium, when the LEV release from the LEV-loaded formulations was examined (Figure 6), among LEV 30, LEV+CBZ and LEV 150 formulations, the slowest LEV release was obtained for the 
LEV 150 formulation and about $80 \%$ of LEV was released from the LEV 150 formulation at 1 hour. About $90 \%$, $96 \%$ and $85 \%$ of CBZ were released from LEV+CBZ, CBZ 120 and CBZ 150 formulations, respectively, at 3 hours (Figure 6).

\section{PB pH 6.8}
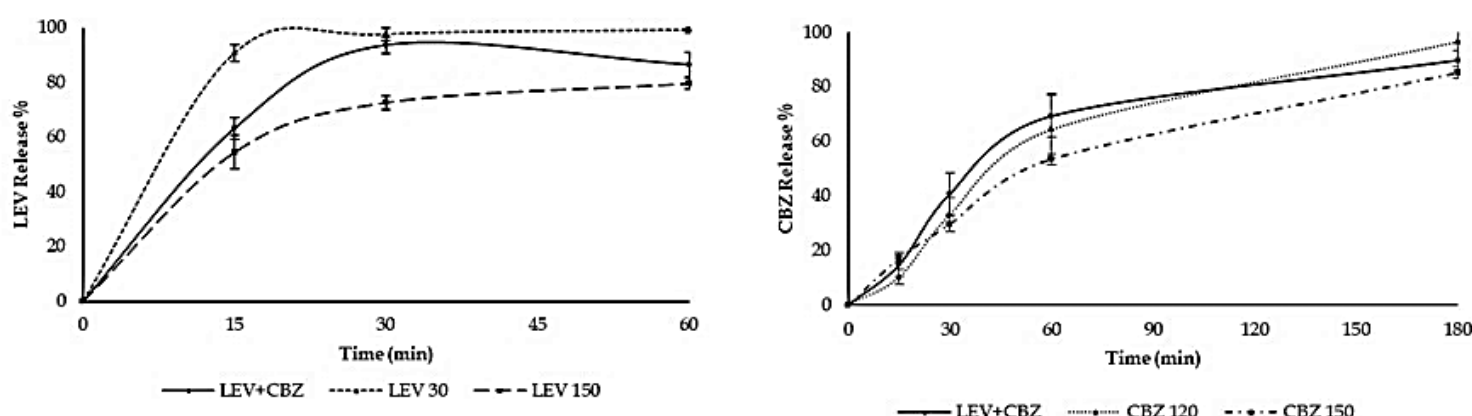

$\mathrm{HCl} \mathrm{pH} 1.2$
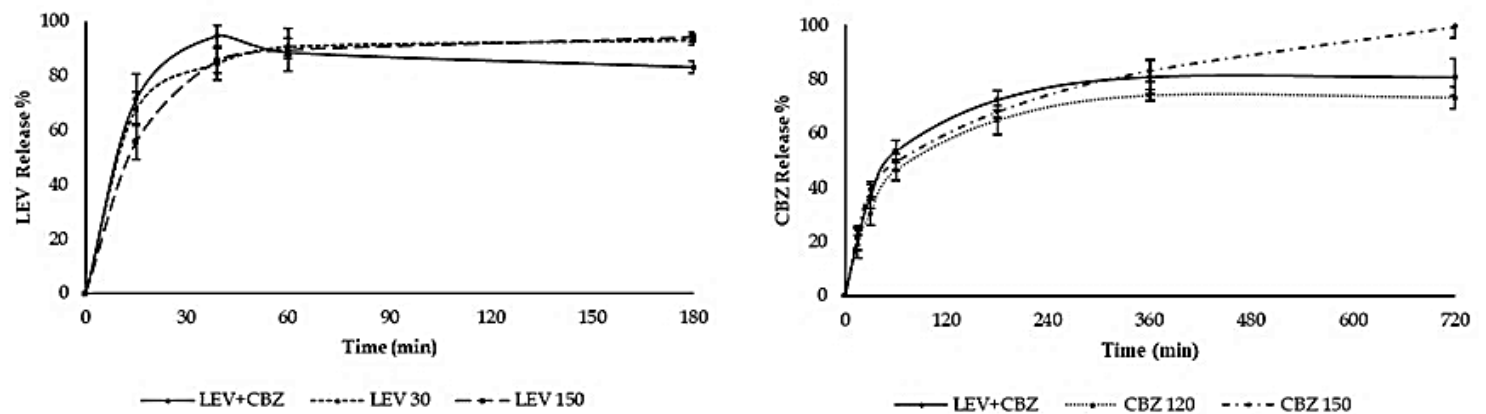

Figure 6. Drug release\% from bead formulations in $\mathrm{PB}$ pH 6.8 and $\mathrm{HCl} \mathrm{pH} 1.2$ release mediums.

At $\mathrm{HCl} \mathrm{pH} 1.2$ release medium, approximately $83 \%, 93 \%$ and $94 \%$ of $\mathrm{LEV}$ were released from LEV+CBZ, LEV 30 and LEV 150 formulations, respectively, at 3 hours (Figure 6). Among these formulations, the fastest release was achieved for the $\mathrm{LEV}+\mathrm{CBZ}$ formulation and about $95 \%$ of $\mathrm{LEV}$ was released from the formulation at $30 \mathrm{~min}$. About $81 \%$ and $74 \%$ of CBZ were released from LEV+CBZ, CBZ 120, respectively, at 6 hours and $99 \%$ of CBZ was released from CBZ 150 formulation at 12 hours (Figure 6).

In both release medium, a burst release of LEV from LEV+CBZ, LEV 30 and LEV 150 formulations was observed. The burst release is due to the presence of LEV on the surface of the beads and also the high water solubility of LEV. The burst release obtained at the beginning of many controlled-release processes is due to pore diffusion, surface desorption or the lack of a diffusion front barrier for regulation of the diffusive process [25]. An initial burst release for bead formulations was reported in some studies [26, 27].

When evaluated CBZ release from beads in both release media, a faster CBZ release was observed in PB $\mathrm{pH} 6.8$ compared to that in $\mathrm{HCl} \mathrm{pH} 1.2$ medium. Calcium-alginate matrix structure was swollen due to the displacement of calcium with cations in PB and as a result, the network structure became largely loose and a faster CBZ release was obtained.

Rajendran and Basu [28] prepared AL beads containing nimodipine. They reported that the swelling degree of beads and drug release from beads increased due to the exchange of the $\mathrm{Ca}^{+2}$ ion with $\mathrm{Na}^{+1}$ in $\mathrm{PB}$ $\mathrm{pH}$ 6.8. Similar results were reported by Tomida et al. [29].

\section{CONCLUSION}

In this study, LEV or CBZ or LEV+CBZ-loaded AL beads were prepared and characterized successfully. The EE\% of LEV was influenced by the high water solubility of LEV. Besides, the $\mathrm{pH}$ of the release medium and the high water solubility of LEV affected the drug release rate from beads. LEV+CBZ-loaded AL beads might be useful for the polytherapy of epilepsy. 


\section{MATERIALS AND METHODS}

\subsection{Materials}

LEV and CBZ were generous gifts from DEVA Holding A.Ş. (İstanbul, Turkey) and Biofarma İlaç San. Tic. A.Ş. (İstanbul, Turkey), respectively. Sodium Alginate was obtained from Sigma-Aldrich (USA). All other chemicals and reagents were of analytical grade.

\subsection{Methods}

\subsubsection{Preparation of the drug-loaded AL beads}

LEV+CBZ-AL beads were prepared by using ionotropic gelation technique. LEV (30 mg) was dissolved in AL aqueous solution ( $2 \% \mathrm{w} / \mathrm{v})$ containing $1 \%(\mathrm{w} / \mathrm{v})$ of sodium lauryl sulphate (SLS). CBZ $(120 \mathrm{mg})$ solution in DMSO was added dropwise to AL solution containing LEV while mixed on magnetic stirrer. Later, the bubble-free solution containing drugs and polymer was dropped through a syringe needle (26 gauge) into $13.3 \%(\mathrm{w} / \mathrm{v})$ of calcium chloride solution on magnetic stirrer at $800 \mathrm{rpm}$. At room temperature, the formed beads were further mixed for $15 \mathrm{~min}$ in gelling medium, and then the beads were filtered. The beads were lyophilized at $-55{ }^{\circ} \mathrm{C}$ and 0.021 mbar for 24 hours (Alpha 1-2 LD Plus, Martin Christ, Germany). The beads containing only LEV or CBZ were prepared the same way in method given above. The codes and combinations of bead formulations were given in Table 3 .

Table 3. Formulations' codes and combinations.

\begin{tabular}{cccccc}
\hline $\begin{array}{c}\text { Formulation } \\
\text { Codes }\end{array}$ & $\begin{array}{c}\text { LEV } \\
(\mathbf{m g})\end{array}$ & $\begin{array}{c}\text { CBZ } \\
(\mathbf{m g})\end{array}$ & $\begin{array}{c}\text { SLS } \\
(\mathbf{1 \%} \% \mathbf{w} / \mathbf{v})\end{array}$ & $\begin{array}{c}\text { Sodium AL } \\
(\mathbf{2 \%} \text { w/v })\end{array}$ & $\begin{array}{c}\mathbf{C a C l}_{\mathbf{2}} \\
(\mathbf{1 3 . 3 \%} \mathbf{w} / \mathbf{v})\end{array}$ \\
\hline LEV+CBZ & 30 & 120 & + & + & + \\
LEV 30 & 30 & - & + & + & + \\
LEV 150 & 150 & - & + & + & + \\
CBZ 120 & - & 120 & + & + & + \\
CBZ 150 & - & 150 & + & + & + \\
B & - & - & + & + & + \\
\hline
\end{tabular}

\subsubsection{The particle size and surface morphology of beads}

The particle size of beads $(n=150)$ was determined by Vernier calipers. The surface morphologies of the beads were evaluated through scanning electron microscope (SEM, Zeiss Sigma 300, Germany) images of lyophilized beads after coating with gold and also digital photographs of wet beads.

\subsubsection{The analysis of FT-IR}

A Bruker VERTEKS 70v model FT-IR (Bruker, Germany) was used to record the IR spectra of AL, LEV, CBZ, blank and drugs-loaded beads prepared in $\mathrm{KBr}$ disks in the region of $400-4000 \mathrm{~cm}^{-1}$.

\subsubsection{Drugs contents of the AL-beads}

$20 \mathrm{mg}$ lyophilized beads in $7.5 \mathrm{~mL}$ of ultrapure water in amber vials were sonicated for $30 \mathrm{~min}$ and later, $7.5 \mathrm{~mL}$ of methanol was added to the mixture and mixed at $600 \mathrm{rpm}$ for 3 hours in the dark condition. After centrifugation at $12500 \mathrm{rpm}$ for 15 minutes at $15^{\circ} \mathrm{C}$, the supernatant was filtered using membrane filter $(0.22 \mu \mathrm{m})$ and the drugs contents in filtrate for each sample were then measured using a validated HPLC-UV (Thermo Finnigan Surveyor, USA) method at $230 \mathrm{~nm}$.

\subsubsection{Swelling properties of the AL-beads}

The pre-weighed lyophilized beads were immersed in two different buffer solutions $\mathrm{HCl} \mathrm{pH} 1.2$ and in the phosphate buffer (PB) $\mathrm{pH} 6.8$ at $37 \pm 0.5{ }^{\circ} \mathrm{C}$ and the weight changes of beads were determined at predetermined time intervals until complete dissolution of the beads. The percent swelling was determined using the following equation (Equation 1).

$$
\text { Swelling } \%=100 \times\left(\frac{\mathrm{Wt}-\mathrm{W} 0}{\mathrm{~W} 0}\right)
$$

$\mathrm{Wt}$ : the weight of beads at time $(\mathrm{mg}) ; \mathrm{W}_{0}$ : the initial weight of beads $(\mathrm{mg})$.

The experiments were carried out in triplicate and data as average was given. 


\subsubsection{In vitro release studies}

The release studies were performed in the both release mediums ( $\mathrm{HCl} \mathrm{pH} 1.2$ and $\mathrm{PB} \mathrm{pH} 6.8) .20 \mathrm{mg}$ lyophilized beads were suspended in $15 \mathrm{~mL}$ of release medium in amber vials and then the vials were placed in horizontal water bath shaker $(50 \mathrm{rpm})$ at $37 \pm 0.5^{\circ} \mathrm{C}$. The samples $(1 \mathrm{~mL})$ were withdrawn from the release medium at predetermined time intervals and later the same volume of fresh release medium was added to the vials. The samples were centrifuged at $12500 \mathrm{rpm}$ for $15 \mathrm{~min}$ and the supernatants were filtered using membrane filters $(0.22 \mu \mathrm{m})$ and the drugs contents in filtrate for each sample was measured by means of a validated using a validated HPLC-UV method at $230 \mathrm{~nm}$.

\subsubsection{Statistical analysis}

The obtained data were expressed as mean \pm SD. SPSS Statistics 22.0 program (SPSS Inc., Chicago, USA) was used for statistical evaluations. Mann-Whitney $U$ test and Wilcoxon test (sample sizes $<30$ ) and also ANOVA test (samples sizes $>30)$ were performed for experimental data $(\mathrm{p}<0.05$ presents the statistical significance).

Acknowledgements: This study was supported by Atatürk University Research Foundation (project number: 6420)

Author contributions: Concept - M.Ç.; Design - M.Ç.; Supervision - M.Ç.; Materials - M.Ç., A.B.U., B.K.; Data Collection and/or Processing - A.B.U., B.K.; Analysis and/or Interpretation - M.Ç., A.B.U., B.K., F.D.M.; Literature Search - M.Ç., A.B.U., B.K., F.D.M.; Writing - M.Ç.; Critical Reviews - M.Ç., A.B.U., B.K., F.D.M.

Conflict of interest statement: The authors declare that there is no conflict of interests.

\section{REFERENCES}

[1] Kumar P, Jhanjee A, Bhatia MS. Lacosamide: A new antiepileptic drug. Delhi Psychiatry J. 2010; 13(2): 356-366.

[2] Devinsky O, Vezzani A, O’Brien TJ, Jette N, Scheffer IE, De Curtis M, Perucca P. Epilepsy. Nat Rev Dis Primers. 2018; 3: 18024. [CrossRef]

[3] Florek-Luszczki M, Wlaz A, Luszczki JJ. Interactions of levetiracetam with carbamazepine, phenytoin, topiramate and vigabatrin in the mouse $6 \mathrm{~Hz}$ psychomotor seizure model - A type II isobolographic analysis. Eur J Pharmacol. 2014; 723: 410-418. [CrossRef]

[4] Rosati A, De Masi S, Guerrini R. Antiepileptic drug treatment in children with epilepsy. CNS Drugs. 2015; 29(10): 847-863. [CrossRef]

[5] Kumar A, Kadian R. Levetiracetam. [Updated 2018 Apr 28]. In: StatPearls [Internet]. Treasure Island (FL): StatPearls Publishing; 2018 Jan. http:/ / www.ncbi.nlm.nih.gov/books/NBK499890 (accessed August 27, 2018).

[6] Drugs@FDA: FDA Approved Drug Products. http://www.accessdata.fda.gov/scripts/cder/daf/ (accessed August $27,2018)$.

[7] FDA-Orange Book: Approved Drug Products with Therapeutic Equivalence Evaluations. http://www.accessdata.fda.gov/scripts/cder/ob/ (accessed August 27, 2018).

[8] Fricke-Galindo I, LLerena A, Jung-Cook H, López-López M. Carbamazepine adverse drug reactions. Expert Rev Clin Pharmacol. 2018; 11(7): 705-718. [CrossRef]

[9] Maan JS, Saadabadi A. Carbamazepine. [Updated 2018 Jan 4]. In: StatPearls [Internet]. Treasure Island (FL): StatPearls Publishing; 2018 Jan. http://www.ncbi.nlm.nih.gov/books/NBK482455 (accessed August 27, 2018).

[10] Sweetman SC, Martindale: The Complete Drug Reference, thirty-sixth ed., The Pharmaceutical Press, London, UK 2009.

[11] Belalia F, Djelali N. Investigation of swelling/adsorption behavior of calcium alginate beads. Rev Roum Chim. 2016; 61(10): 747-754.

[12] Bajpai SK, Kirar N. Swelling and drug release behavior of calcium alginate/poly (sodium acrylate) hydrogel beads. Des Monomers Polym. 2016; 19(1): 89-98. [CrossRef]

[13] Takka S, Acartürk F. Calcium alginate microparticles for oral administration: I: effect of sodium alginate type on drug release and drug entrapment efficiency. J Microencapsul. 1999; 16(39): 275-290. [CrossRef] 
[14] Donati I, Feresini M, Travan A, Marsich E, Lapasin R, Paoletti S. Polysaccharide-based polyanion-polycationpolyanion ternary systems. A preliminary analysis of interpolyelectrolyte interactions in dilute solutions. Biomacromolecules. 2011; 12(11): 4044-4056. [CrossRef]

[15] Tønnesen HH, Karlsen J. Alginate in drug delivery systems. Drug Dev Ind Pharm. 2002; 28(6): 621-630. [CrossRef]

[16] Zohar-Perez C, Chet I, Nussinovitch A. Irregular textural features of dried alginate-filler beads. Food Hydrocoll. 2004; 18(2): 249-258. [CrossRef]

[17] Najafi-Soulari S, Shekarchizadeh H, Kadivar M. Encapsulation optimization of lemon balm antioxidants in calcium alginate hydrogels. J Biomater Sci Polym Ed. 2016; 27(16): 1631-1644. [CrossRef]

[18] El-Kamel AH, Al-Gohary OM, Hosny EA. Alginate-diltiazem hydrochloride beads: optimization of formulation factors, in vitro and in vivo availability. J Microencapsul. 2003; 20(2): 211-225. [CrossRef]

[19] Verma A, Sharma M, Verma N, Pandit JK. Floating alginate beads: studies on formulation factors for improved drug entrapment efficiency and in vitro release. Farmacia. 2013; 61(1): 143-161.

[20] Patel YL, Sher P, Pawar AP. The effect of drug concentration and curing time on processing and properties of calcium alginate beads containing metronidazole by response surface methodology. AAPS Pharm Sci Tech. 2006; 7(4): E1-E7. [CrossRef]

[21] Huang X, Xiao Y, Lang M. Micelles/sodium-alginate composite gel beads: A new matrix for oral drug delivery of indomethacin. Carbohydr Polym. 2012; 87(1): 790-798. [CrossRef]

[22] Takka S, Acartürk F. Calcium alginate microparticles for oral administration: II effect of formulation factors on drug release and drug entrapment efficiency. J Microencapsul. 1999; 16(39): 291-301. [CrossRef]

[23] Jao W, Ho L, Chen Z. Evaluation of the drug release mechanism of pH-sensitive calcium alginate hydrogels in simulated physiological fluids. J China Univ Sci Tech. 2010; 42: 37-61.

[24] Tous S, Fathy M, Fetih G, Gad SF. Preparation and evaluation of ketoprofen-loaded calcium alginate beads. Int J PharmTech Res. 2014; 6(3): 1100-1112.

[25] Huang X, Brazel CS. Analysis of burst release of proxyphylline from poly(vinyl alcohol) hydrogels. Chem Eng Commun. 2003; 190(4): 519-532. [CrossRef]

[26] Srinatha A, Pandit JK, Singh S. Ionic cross-linked chitosan beads for extended release of ciprofloxacin: in vitro characterization. Indian J Pharm Sci. 2008; 70(1): 16-21. [CrossRef]

[27] Huanbutta K, Nernplod T, Akkaramongkolporn P, Sriamornsak P. Design of porous Eudragit@ L beads for floating drug delivery by wax removal technique. Asian J Pharm Sci. 2017; 12(3): 227-234. [CrossRef]

[28] Rajendran A, Basu SK. Alginate-chitosan particulate system for sustained release of nimodipine. Trop J Pharm Res. 2009; 8(5): 433-440. [CrossRef]

[29] Tomida H, Mizuo C, Nakamura C, Kıryu S. Imipramine release from Ca-Alginate gel beads. Chem Pharm Bull. 1993; 41(8): 1475-1477. [CrossRef] 